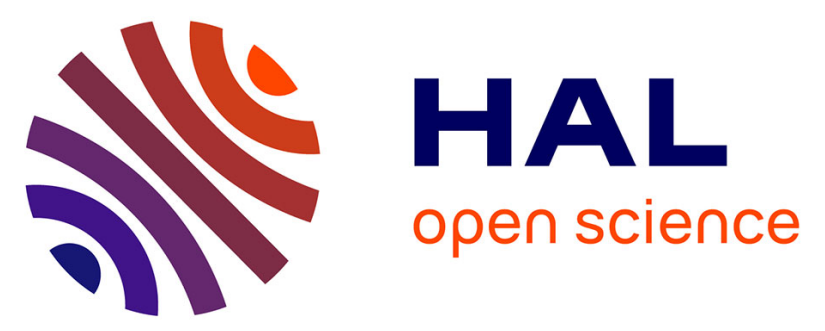

\title{
HST WFC3 G141 data analysis: exploring the transition from Super-Earth to Sub-Neptune
}

\author{
Amélie Gressier, Emmanuel Marcq, Jean-Philippe Beaulieu, Benjamin
}

Charnay

\section{- To cite this version:}

Amélie Gressier, Emmanuel Marcq, Jean-Philippe Beaulieu, Benjamin Charnay. HST WFC3 G141 data analysis: exploring the transition from Super-Earth to Sub-Neptune. European Planetary Science Congress. EPSC 2021, Sep 2021, Virtual Meeting, France. 10.5194/epsc2021-194 . insu-03313633

\section{HAL Id: insu-03313633 \\ https://hal-insu.archives-ouvertes.fr/insu-03313633}

Submitted on 4 Aug 2021

HAL is a multi-disciplinary open access archive for the deposit and dissemination of scientific research documents, whether they are published or not. The documents may come from teaching and research institutions in France or abroad, or from public or private research centers.
L'archive ouverte pluridisciplinaire HAL, est destinée au dépôt et à la diffusion de documents scientifiques de niveau recherche, publiés ou non, émanant des établissements d'enseignement et de recherche français ou étrangers, des laboratoires publics ou privés.

\section{(c)(1)}

Distributed under a Creative Commons Attribution| 4.0 International License 
EPSC Abstracts

Vol. 15, EPSC2021-194, 2021

https://doi.org/10.5194/epsc2021-194

European Planetary Science Congress 2021

(C) Author(s) 2021. This work is distributed under

the Creative Commons Attribution 4.0 License.

\title{
HST WFC3 G141 data analysis: exploring the transition from Super- Earth to Sub-Neptune
}

\author{
Amélie Gressier ${ }^{1,2,3}$, Emmanuel Marcq ${ }^{1}$, Jean-Philippe Beaulieu ${ }^{2}$, and Benjamin Charnay ${ }^{3}$ \\ ${ }^{1}$ LATMOS, CNRS, Sorbonne Université UVSQ, 11 boulevard d'Alembert, F-78280 Guyancourt, France \\ ${ }^{2}$ IAP, Sorbonne Université, UPMC Université Paris 6 et CNRS, UMR 7095, Institut d'Astrophysique de Paris, 98 bis bd Arago, \\ 75014 Paris, France \\ ${ }^{3}$ LESIA, Observatoire de Paris, Université PSL, CNRS, Sorbonne Université, Université de Paris, 5 place Jules Janssen, 92195 \\ Meudon, France
}

Exoplanets with size between the Earth and Neptune (1-4R $\square$ ) do not have any equivalent in our Solar System and remain challenging to characterize. Yet, there are ubiquitous in the Galaxy and Fulton et al. (2017) showed that their distribution (number of planets per star vs radius) is bimodal highlighting a gap in the number of planets around 1.7R $\square$. Planets with a radius below 1.7R $\square$ are thought to be mostly rocky planets, and called Super-Earth, above this limit planets are most likely made of gas and called Sub-Neptune. We made use of the available data from the Hubble Space Telescope in Near-Infrared (HST WFC3 G141) and gathered 18 transmission spectra of planets with size below $6 \mathrm{R} \square$ to study the transition between rocky and gaseous planets. First, we used TauREx3 (Al-Refaie et al. 2019), a Bayesian retrieval code, to rule out atmospheric scenarios. We proved that a primary clear atmosphere dominated by Hydrogen and Helium is rejected with more than $3 \sigma$ for a large majority of planets in the sample. Then, we measured the amplitude of the spectra in the water absorption band (around $1.4 \mu \mathrm{m}$ ) and compared observational values to simulated ones using a self-consistent modeling code ExoREM (Baudino et al. 2015; Charnay et al. 2018). We explored the connection between the water absorption amplitudes and the temperature by setting the stellar and planetary parameters to those of HD $3167 \mathrm{c}(2.7 \mathrm{R} \square, 8.33 \mathrm{M} \square)$ and trying different metallicities $(1,10,100$ and $1000 \times$ solar $)$, cloud compositions and temperatures (300-1200K). 